\title{
Uma referência teórica e metodológica para os estudos sobre a educação da força de trabalho*
}

\section{Carlos Antonio Gomes ${ }^{* *}$}

Resumo: Esse é um estudo bibliográfico e apresenta o surgimento da sociologia do trabalho francesa, quando o declínio do taylorismo-fordismo e do empobrecimento do trabalho se revelaram. Dentre outras clivagens nos estudos sobre o mundo do trabalho, a sociologia do trabalho francesa fundou um campo de estudos e desenvolveu uma metodologia eficiente e sofisticada para investigar a qualificação da força de trabalho sob o modo de produção capitalista. O objetivo aqui intencionado é buscar elementos teóricos para a compreensão das novas demandas por trabalho enriquecido e qualificado que a nova economia e o novo estágio da acumulação capitalista impõem ao sistema educacional e ao de formação profissional. A conclusão desse estudo é que, no Brasil, a metodologia francesa ainda é, em grande parte, ignorada pelos pesquisadores, sendo que esse comportamento tem comprometido a qualidade das pesquisas sobre a qualificação da força de trabalho.

Palavras-chave: educação profissional; história da educação; educação e trabalho.

Abstract: This is a bibliographical study and presents the appearance of French sociology of work, when the decline of Taylorism and Fordism and the impoverishment of the work is revealed. Among other cleavages in studies of the world of work, sociology of work French founded a field of study and developed a sophisticated and efficient methodology to investigate the qualification of the workforce under the capitalist mode of production. The goal here is to seek meaning theoretical elements for understanding the new demands for skilled labor and enriched the new economy and the new stage of capitalist accumulation impose the educational system and vocational training. The conclusion of this study is that, in Brazil, the French methodology is still largely ignored by researchers, and this behavior has compromised the quality of research on the qualifications of the workforce.

Keywords: professional education, history of education, education and work.

* Esse artigo é uma condensação do primeiro capítulo da minha tese de doutorado denominada A qualificação resignada. A má formação da força de trabalho como um problema estrutural do desenvolvimento brasileiro, defendida, em 2011, pela Faculdade de Educação (FE) da Universidade Estadual de Campinas (Unicamp).

** Mestre e doutor em Educação pela Faculdade de Educação (FE) da Unicamp; especialista em educação profissional e mercado de trabalho; pesquisador da Fundação para o Desenvolvimento da Unesp (Fundunesp) (prof.carlosgomes@gmail.com). 


\section{Introdução}

Em pleno século XXI - quando os sistemas econômicos e os produtivos perseguem a competitividade por meio da centralidade depositada na excelência do capital humano, elegendo a educação como o cerne do debate sobre o desenvolvimento econômico e social - a política educacional brasileira ainda tateia cegamente, orientando-se pelas recomendações do Banco Mundial. Hoje, não restam dúvidas que o Brasil vivencia uma crise de recursos humanos que compromete o seu desenvolvimento e a sua participação nas relações internacionais de troca.

Essa omissão do Estado tem feito com que o debate sobre a educação brasileira continue no centro das preocupações dos educadores, ativistas e de muitos outros estudiosos. Todavia, após a virada do século, o capital também aderiu ao movimento por uma revolução educacional, quando uma miríade de pesquisas constatou que a má qualidade do capital humano compromete a produtividade e as taxas de retorno das empresas.

Todavia, há uma nítida tentativa governamental de esconder a ineficiência da política educacional, para não desarticular a projeção política e eleitoral que se fez para o ex-ministro da educação F. Haddad. Na Faculdade de Educação e no Instituto de Economia da Unicamp, os pesquisadores M. P. Leite e M. Pochmann argumentam que a crise de recursos humanos é um discurso que as empresas se utilizam a fim de justificar o aumento real dos salários. Na Faculdade de Educação da Universidade Federal da Bahia (UFB), o pesquisador governista A. Bondi Lima diz que para revolucionar a educação brasileira basta fundamentar-se um campo bourdieursiano de estudos. De 2009 a 2011, houve, inclusive, uma bizarra tentativa por parte do Instituto de Pesquisa Econômica Aplicada (IPEA) de macular os dados sobre a educação brasileira, escondendo, assim, a crise de mão de obra qualificada.

Diante de tantos dados comprobatórios da má qualidade da educação brasileira, mas poucos sobre a educação profissional, desde o ano 2000, tenho-me debruçado sobre esse campo de estudos. Além de outros trabalhos, ${ }^{1}$ em 2011 publiquei aquele que, creio, faz o mais amplo diagnóstico da política e do sistema de educação profissional do Brasil.²

Além da apresentação de dados estatísticos sobre a má formação da força de trabalho, a minha tese, no seu primeiro capítulo, também promove uma revisão bibliográfica a fim de subsidiar o debate metodológico acerca dos elementos mais relevantes nas investigações sobre a relação entre a educação e o trabalho. A apresentação da vasta e profícua produção da sociologia do trabalho francesa objetiva a despertar a atenção dos pesquisadores brasileiros para os elementos metodológicos desenvolvidos por essa corrente.

Para a sociologia do trabalho francesa, dois condicionantes impactam a demanda educacional da força de trabalho: a divisão do trabalho e o sistema tecnológico que interage com a produção. Com efeito, o entendimento da crise do capital humano no Brasil, necessariamente, creio, passa pela observação desses elementos, sendo que ao longo desse artigo exponho em detalhes a argumentação dessa corrente investigativa.

1 Inclusive GOMES, C. Produção flexível e degradação da força de trabalho no Brasil. Dissertação de Mestrado. Universidade Estadual de Campinas - FE, 2006.

2 GOMES, C. A qualificação resignada. A má formação da força de trabalho como um problema estrutural do desenvolvimento brasileiro. Tese de doutorado. Universidade Estadual de Campinas - FE, 2011. 


\section{O idílio do socialismo utópico.}

A ideia de uma sociedade igualitária que mobilizou os socialistas do século XIX não seria sustentável sem que também se construísse um idílio para o homem que dela faria parte; isso porque, ainda que tenham tomado caminhos distintos no curso da história, todas as filosofias filiadas ao lluminismo são, por essência, antropocêntricas, uma vez que reconduzem o homem ao centro das preocupações, lugar do qual ele fora destituído ao final da Antiguidade. Ao projetar a civilização do futuro, o socialismo idealizou uma sociedade que seria nova em decorrência das transformações a serem levadas a efeito no regime de propriedade e nas relações de produção, sendo que o novo homem que dela emergiria seria totalmente liberto do reino das necessidades e de todos os desígnios do capitalismo, especialmente, daquele que o alienou pela apropriação do seu conhecimento produtivo.

Assim, a reconquista desse conhecimento corporifica-se na proposta de ressurreição do homo faber, ideia que perpassa parte considerável da literatura socialista do século XIX, desde o anarquismo, socialismo utópico até o marxismo. Portanto, o socialismo é a primeira e a única corrente do pensamento a debater com profundidade a questão da qualificação do homem para o trabalho e propor a sua emancipação por meio da eliminação do trabalho alienado e fragmentário, praticado pelo modo de produção capitalista.

Dentre os pensadores românticos que debateram a qualificação para o trabalho, Robert Owen foi pioneiro e o mais audaz. Capitalista da indústria têxtil que ascendeu pelo trabalho, Owen tornou-se um reformista obstinado, ao estarrecerse com as condições de trabalho no Reino Unido, no século XIX. Preocupou-se com o bem-estar dos seus operários, diminuindo a jornada de trabalho, proibindo o trabalho das crianças, construindo habitações salutares, propiciando mercados para vender gêneros de primeira necessidade a preços acessíveis aos trabalhadores e remunerou-os dignamente; também se dedicou à qualificação dos funcionários, construindo-lhes escolas.

Crítico da divisão do trabalho, Owen fez experimentações de recomposição das tarefas nas suas indústrias; para ele, a divisão do trabalho era a fonte da desmoralização, indignidade, miséria e de todas as formas de desperdícios. Assim, defendia para os trabalhadores uma formação escolar abrangente e pluridisciplinar que lhes possibilitasse serem os protagonistas da produção e, com esse intuito, foi o primeiro a formular a proposta da educação politécnica. Ao descobrir os limites das suas ações isoladas nas suas indústrias, Owen tornou-se um crítico do capitalismo; nessa evolução, descobriu as virtudes do cooperativismo, em que, para serem seres absolutos na produção, os trabalhadores necessitariam de total autonomia em relação ao capital. Foi expulso do Reino Unido, migrando para os Estados Unidos, onde se dedicou à montagem de estruturas produtivas comunitárias, que jamais prosperaram.

O humanismo militante de Owen nunca foi além do romantismo que mobilizou muitos dos homens e mulheres do seu tempo. Todavia, as suas ideias foram, sobremaneira, carregadas de simbolismo, de modo que nem as acirradas controvérsias entre os marxistas e os socialistas utópicos serviram de anteparo entre ele e Marx, que, invariavelmente, Ihe fez menção. $O$ seu ativismo permanece vivo ainda que errônea e crassamente interpretado como filantrópico ou pioneirismo empresarial que, nos dias presentes, é referencial para as empresas socialmente responsáveis. Todavia, além do humanismo, a originalidade das suas ideias consiste em vislumbrar 
que a degradação moral que acometia o homem destituído do seu saber produtivo não era o fruto de uma evolução natural e inexorável, podendo ser revertida por mudanças nas formas de produção e pela educação dos trabalhadores.

Marx foi contemporâneo do capitalismo concorrencial e, a despeito de ter presenciado a mais severa degradação das condições de trabalho - as condições da classe operária na Inglaterra, no século XIX - não testemunhou a mais brutal degradação do saber produtivo, que se deu com latência mais tarde, a partir do século XX, com a consolidação do taylorismo e da Administração Científica do Trabalho. Mesmo assim, observando o empobrecimento do trabalho que ocorria sob a regência do capital e pelo emprego da divisão do trabalho da grande indústria e da maquinaria da Primeira Revolução Industrial, a sua perspicácia possibilitou-lhe antever uma situação mais degradante, no futuro, e, ao mesmo tempo, imaginar um modelo ideal de educação que libertaria o homem da alienação imposta pelo capital.

Em Anti-Düring, compartilhando muitos dos princípios comuns a Marx, Engels ${ }^{3}$ retoma a ideia do homo faber, argumentando que, na sociedade fundada no igualitarismo, as diferenças entre planejadores e executores da produção seriam abolidas, com a formação de uma raça de produtores municiada dos mais profundos conhecimentos científicos e tecnológicos sobre a produção industrial, conhecimentos esses que Ihes seriam auferidos pela educação politécnica.

Por mais que se reconheça o marxismo como a ciência que desnudou as leis da sociedade capitalista impetrando uma ruptura em relação ao pensamento utópico, não se pode negar que, tal como os românticos, o tema da qualificação está presente em boa parte dos seus trabalhos, porém, ele nunca foi objeto de um tratamento específico.

\section{A politecnia soviética e a pedagogia da utopia}

A ideia do homem produtivamente emancipado é de uma força tão simbólica para o pensamento socialista que, mesmo já tendo se explicitado como uma ditadura que só se manteve pelo terror e tendo construído uma sólida estrutura industrial tendo por base o taylorismo-fordismo, o regime soviético continuou a alimentar o discurso ideológico da transição para a sociedade sem classes com todas as suas virtudes, entre elas, a introdução da educação politécnica, que criaria as bases para a consagração do homem produtivamente emancipado.

Dentre os problemas cruciais da União das Repúblicas Socialistas Soviéticas (URSS) nos primeiros anos após a "Revolução de Outubro" estava o da industrialização. O parque fabril herdado do regime dos czares - apesar de ter conferido à Rússia o status de economia industrializada - era de segunda grandeza quando comparado às estruturas ocidentais, que se modernizavam velozmente. Conforme o demonstra E.H. Carr, o fracasso das tentativas iniciais de modernização produtiva levou os líderes a buscarem nas experiências ocidentais - especialmente na norte-americana - a solução para o problema do desenvolvimento soviético. Concorria a favor da industrialização a toque-de-caixa a memória ainda viva da Primeira Guerra Mundial, que alertou a nomenklatura para o fato de que a sobrevivência do Estado, em primeira instância, dependeria da sua capacidade industrial. ${ }^{4}$

3 ENGELS, F. Anti-Dühring. Rio der Janeiro: Paz e Terra, 1979.

4 CARR, E.H. A revolução russa de Lênin a Stalin. Rio de Janeiro: Zahar, 1981. 
Lênin, os líderes mais proeminentes e até mesmo N. Krupskaia - defensora do ensino politécnico - contraditoriamente, viam a Administração Científica do Trabalho como a verdadeira ciência da industrialização. De certo que E. Wilson exagerou quando sugeriu que a estrutura do Partido Bolchevista - construída de cima para baixo, com grande centralização no alto comissariado - havia sido inspirada no modelo organizacional de Taylor; mas não estava destituído de razão quando atribuiu a Lênin o apelido de o grande gerente, em virtude do seu desvelado apreço ao taylorismo. ${ }^{5} \mathrm{~A}$ verdade é que o regime fez uma opção pelo taylorismo para a industrialização da União Soviética, confessando que os fins justificam os meios. A célebre frase proferida, em 1987, pelo líder chinês Deng Xiaoping - "Não importa a cor do gato; o importante é que pegue o rato" - embora se referisse às reformas em andamento na China, expressaria com perfeição a importância dada pelos líderes soviéticos aos princípios, quando se tratava de defender o poder.

As diferenças entre o mundo desenvolvido e o subdesenvolvido não se apresentavam nítidas no início do século XX, quando a Segunda Revolução Industrial e Tecnológica irrompeu, dando início à corrida que elegeria as potências protagonistas da história ao longo do seu curso. ${ }^{6}$ O fenômeno que, nos anos 1950, R. Prebsch qualificaria como fratura estrutural do capitalismo - ou seja, a divisão do capitalismo entre o Centro e a Periferia? tem a sua origem nos processos de modernização iniciados nessa época, sendo que a industrialização constitui o elemento primordial do sucesso das nações. Assim, de um ponto de vista estritamente capitalista, a decisão soviética não guarda tamanha diferença em relação ao processo de industrialização alemão e ao japonês, tendo com eles em comum a ação deliberada do Estado no planejamento da política industrial para a consolidação de uma estrutura produtiva eficiente com resguardo dos interesses nacionais. A diferença é que os comunistas fizeram tudo isso em nome de um pretenso interesse coletivo, quando, na verdade, é sabido que esse jamais se beneficiou das virtudes do desenvolvimento tal como as sociedades ocidentais o fizeram.

Mesmo tendo optado pela industrialização baseada no taylorismo, o ensino politécnico ocupou parte dos debates nos planos quinquenais, a partir de 1930. Em 1931, o Comitê Central do Partido Comunista decidiu que a formação politécnica no ensino formal passaria a ser uma doutrina oficial do Estado, devendo as instituições de ensino preparar-se para tal, inclusive com os recém-criados institutos politécnicos realizando experimentações sobre os efeitos práticos da politecnia. Em 1952, o XIX Congresso do Partido Comunista determinou que o ensino politécnico fosse introduzido nas grandes cidades, a partir de 1955, e em todo o vasto território da União Soviética, a partir de 1960. Todavia, em 1958, constatada a falência do ensino politécnico, N. Kruschev promulgou a reforma educacional que sepultava a politecnia e reintroduzia o ensino tradicional.

Até então, o ensino politécnico havia sido implantado em apenas $10 \%$ das escolas da Rússia e, mesmo assim, com distorções em relação àquilo que havia sido preconizado pelos seus idealizadores; ou seja, desenvolver um espírito lastreado na indissociação entre as artes, ciências, filosofia e os ofícios, de modo a possibilitar ao indivíduo, tanto a preparação para o trabalho, quanto para a reflexão crítica sobre o mundo. Além da prisão de muitos educadores e pedagogos adeptos à po-

5 WILSON, E. Rumo à Estação Finlândia. São Paulo: Companhia das Letras, 1987.

6 BARBOSA de OLIVEIRA, C. A. O processo de industrialização: do capitalismo originário ao capitalismo atrasado. Campinas: Unicamp, 2003.

7 PREBSCH, R. Transformación e derrarollo: la gran tarea de la America Latina. Ciudad de México: Fondo de Cultura Económica, 1970. 
litecnia - ocorrida nos grandes expurgos, a partir de 1935 - outro problema verificado na aplicação do método foi a precariedade do sistema educacional soviético, posto que as escolas não dispunham de estrutura adequada ao ensino aprofundado de ciências. Para Friedmann, "o regime não logrou realizar a profecia de Marx, extirpando do espírito das novas gerações a distinção entre trabalho manual e trabalho intelectual". ${ }^{8}$

A ideia da consagração do homem pleno surgiu e evoluiu concomitantemente à ideia da sociedade sem classes, sendo que em toda a literatura, ambas aparecem indissociadas. Embora o socialismo tenha se tornado causador de impressões, crescentemente, anacrônicas a partir do segundo pós-guerra, esse seu ideal permanece vivo, recuperado pelo capitalismo ao final do século XX sob outra dimensão ideológica. Entre esses fundamentos estão o enriquecimento do trabalho pela recomposição das suas frações anteriormente desmembradas que, aos olhos de muitos, ressurge enquanto possibilidade sob a terminologia de neo-artesanato, e o trabalhador relativamente pleno que, segundo muitos, já reinventado nas indústrias de organização avançada, ressurge sob o nome de polivalente.

\section{O taylorismo e a consagração do homem fracionado}

O longo império da Primeira Revolução Industrial e Tecnológica entrou em declínio a partir de meados do século XIX, quando as suas bases começaram a desmoronar conforme a divisão manufatureira do trabalho e a antiga maquinaria mostravam-se obsoletos ao regime de acumulação de capital. Ao final daquele século, à medida que o conjunto de novas tecnologias de base científica instalavase, também se evidenciava a inadequação da divisão do trabalho que orientara a indústria do capitalismo concorrencial.

O trabalho parcelizado não era novidade ao final do século XIX, quando Taylor iniciou as suas experimentações, posto que ele vinha sendo executado em graus diferenciados pela manufatura e pela grande indústria e defendido por inúmeros pensadores, entre eles A. Smith, Babbage e Fayol. De modo que o feito de Taylor foi aprofundar a sua fragmentação, buscando retirar até a uma última gota de conhecimento e de decisão por parte do operário, acrescentando o controle cronométrico de tempo para a execução de cada tarefa.

O sistema que emergiu da comunhão entre os princípios de Taylor e os de Ford, ainda que parecesse eficiente nas primeiras décadas do século XX, só seria testado no segundo pós-guerra, explicitando a sua falibilidade. Considerando que: (i) essa comunhão só ocorreu por volta de 1911; (ii) ao final da década seguinte a Grande Depressão irrompeu-se, deitando por terra a demanda estadunidense e; (iii) o padrão de consumo norte-americano - tal como se notabilizaria nos Anos Dourados - só se imporia a partir dos anos 1950, então, o sistema produtivo só pôde ser posto a prova por volta dessa década.

Seria conveniente, no entanto, perguntar se a própria Segunda Guerra Mundial não teria certificado a competência do sistema, posto que a estrutura industrial norte-americana supriu com eficiência a demanda de todo o bloco dos países aliados. Para Drucker $^{9}$ a resposta é não, porque a incontestável eficiência da indústria estadunidense durante a guerra não se deveu aos fundamentos tayloristas

8 FRIEDMANN, G. O trabalho em migalhas. São Paulo: Perspectiva, 1972.

9 DRUCKER, P. Prática de administração de empresas. São Paulo: Pioneira, 1981. 
e fordistas. Segundo Drucker, o arranjo clássico da linha de montagem não funcionou a contento quando as encomendas das Forças Armadas requereram um nível pronunciado de diversificação. Em resposta, as empresas fornecedoras do Estado tiveram que recuar em relação a muitos dos princípios de Taylor e de Ford, particularmente, em relação à especialização extremada dos trabalhadores, implantando o rodízio de postos de trabalho o que, de certo modo, redundou numa ampliação das tarefas.

Dentre os muitos erros crassos cometidos por Taylor o que mais se levantou contra ele foi o fato de ter ignorado as reações humanas ante um sistema desenvolvido para tratar homens e mulheres como meras peças da maquinaria. $A$ sua fé devota no tecnicismo do seu método e a sua inobservância do comportamento humano, segundo muitos, o tornaram uma personalidade hostil e, de certo modo, perigosa ao gênero humano, como o percebeu Friedmann; segundo o autor: "apesar de todas as profissões de fé, fáceis de coletar em Taylor, sua influência não serviu de fato à 'primazia da pessoa humana' e lhe foi mesmo perigosamente contrária". ${ }^{10}$ Ainda que o seu sistema tenha-se mostrado eficiente a princípio, as suas contradições evidenciaram-se quando a demanda passou a exigir mais dos trabalhadores, a partir dos anos 1950. Nessa época, Drucker observou como o trabalho rotinizado, monótono e desprovido de sentido corrompia os sistemas nervosos, provocando nos trabalhadores todos os tipos de patologias, desde o tédio até depressão, com consequências desastrosas para a produtividade.

O impacto mais perceptível da parcelização nos aspectos motivacionais se dava pelo rebaixamento do moral das turmas no interior das fábricas, sendo que Drucker observou que, a partir de certo nível de especialização, as vantagens de produtividade entravam em declínio, como o frisou: "Agora começamos a compreender que a divisão do trabalho, como qualquer outro processo, comporta um grau a partir do qual as vantagens decrescem"; ;1 isso em decorrência do fato, ignorado por Taylor, de que o ser humano não pode ser tratado "como se fosse uma máquina-ferramenta feita para uma única operação". ${ }^{12}$

Para Fiori, ${ }^{13}$ a Administração Científica do Trabalho, de saída, já ensejava o antagonismo que a levaria ao cadafalso. Segundo o autor, o que Taylor jamais suspeitou é que os níveis de produtividade que ele e os seus discípulos supunham advir da aplicação estrita dos seus fundamentos, na verdade, deviam-se ao emprego da qualificação tácita dos trabalhadores que, a despeito de estarem submetidos às formas mais extremadas de especialização, nunca desfizeram por inteiro dos seus conhecimentos.

Nos Estados Unidos, com o crescimento da demanda a partir dos anos 1950, a Administração Científica do Trabalho mostrou as suas limitações, levando as empresas a abusarem das experimentações com o alargamento das tarefas. Para Friedmann, o comportamento repulsivo por parte das empresas norte-americanas em relação aos princípios de Taylor evidenciava o acelerado "declínio de uma ortodoxia". ${ }^{14}$ Por mais que aqueles fundamentos tenham provocado um encantamento em muitos dos dirigentes que tentavam industrializar os seus países a toque-de-caixa - como o stablishiment soviético, por exemplo - eles anunciavam

10 FRIEDMANN. O trabalho em migalhas, p.76

11 FRIEDMANN, O trabalho em migalhas, p.64.

12 FRIEDMANN, O trabalho em migalhas, p.66

13 FIORI, J.L. Existe um Estado pós-fordista? Reforma e funções do Estado brasileiro no novo paradigma. São Paulo: ILDESDES, Policy paper $\mathrm{n}^{\circ} 7,1993$, mimeo.

14 FRIEDMANN. O trabalho em migalhas, p.51. 
as suas contradições na própria terra que os gestou, os Estados Unidos. E, ainda que a expansão do padrão norte-americano para a Europa, no segundo pós-guerra, como o demonstrou Harvey, ${ }^{15}$ deva-se ao consenso imposto pelo vencedor - 0 que deu a impressão de que o modelo continuava inabalável - uma década mais tarde a sua agonia se faria sentir explicitamente.

Como exposto, adiante, o surgimento, desenvolvimento e a consolidação de uma escola de administração e de um modelo industrial no Japão, a partir dos anos 1960, dinamitaram as bases do taylorismo-fordismo, acelerando o seu declínio. Para o interesse desse trabalho, o chamado modelo japonês suscita um debate instigante, posto que, para muitos estudiosos, a utopia há muito acalentada de consubstanciação de um paradigma lastreado no trabalho enriquecido estaria se cumprindo, ainda que em menor escala e sob outro viés ideológico. Todavia, os acontecimentos de 2008 - a quebra das grandes montadoras automotivas dos Estados Unidos, ícones da Administração Científica do Trabalho - talvez, no futuro, venham a comprovar que a ortodoxia ainda tenha se arrastado por meio século até emitir o seu derradeiro suspiro.

\section{A ideologia do homem fracionado}

E. Durkheim foi contemporâneo de Taylor e testemunha da transformação do modo de produção capitalista. Os seus esforços para criar um método de investigação sociológica desgarrado das ideias evolucionistas, egressas das ciências naturais, não o ajudaram a refletir sobre a nova divisão do trabalho que emergia sob os ditames de Taylor. Em 1893, Durkheim publicou a Divisão do trabalho social, ${ }^{16} \mathrm{em}$ que defendeu que a fragmentação do trabalho era própria da evolução da vida e fonte da solidariedade entre os trabalhadores. As modalidades de fracionamento do trabalho desprovidas de solidariedade, segundo ele, eram excepcionalmente patológicas, pois se desprendiam da lei natural que regia o desenvolvimento do trabalho.

Para Friedmann, a teoria da solidariedade entre os trabalhadores sob o trabalho parcelado era de tal maneira absurda, que só poderia ser desenvolvida a partir de um preconceito teórico. Afinal, como poderia haver solidariedade diante da tamanha degradação moral que o taylorismo provocava com o avanço da industrialização da era do maquinismo? Friedmann argumenta ainda que, a fim de preservar a inviolabilidade da sua teoria, Durkheim teria que considerar como patológicas quase todas as modalidades de trabalho do capitalismo monopolista. ${ }^{17}$

Na visão do estudioso, há um alinhamento indisfarçável entre as ideias de Durkheim e as de Taylor sobre a divisão do trabalho, o que poderia levar a crer que as pressões advindas daquela época de grandes disrupções fizeram o primeiro retroceder, buscando guarida metodológica no evolucionismo. Entretanto, considerando que Durkheim viveu numa época em que as grandes questões da sociedade capitalista já haviam sido explicadas por Marx, Engels e outros, a sua teoria sobre a divisão do trabalho é acientífica, posto que todos os instrumentos metodológicos já estavam ao alcance das mãos, sem que ele os empregasse.

15 HARVEY, D. A condição pós-moderna: uma pesquisa sobre as origens da mudança cultural. São Paulo: Loyola, 1998.

16 DURKHEIM, E. A divisa do trabalho social. São Paulo: Martins Fontes, 1977.

17 FRIEDMANN. O trabalho em migalhas, p.121. 
Taylor jamais foi um cientista; foi um homem prático, perspicaz, sistemático e, talvez, o mais proeminente dentre os tipos de personalidades que levaram Weber ${ }^{18}$ a eleger a ética religiosa como o motor do espírito do capitalismo. Para Friedmann, ${ }^{19}$ Taylor jamais passou de um engenheiro fascinado pela produtividade, preso ao microcosmo da fábrica e incapaz de perceber as macroestruturas da política e das relações sociais. Em todas as análises, Taylor aparece como uma pessoa sem prodígio algum e desnudada de uma cultura política refinada, incapaz, portanto, de formular uma teoria para o controle social. E, sendo os seus fundamentos de organização do trabalho tão desagregadores, o que manteria os trabalhadores quietos nas fábricas? Certamente, a teoria de Durkheim jamais poderia ter cumprido esse papel, posto que o seu acanhamento conceitual jamais lhe permitiria escapar dos círculos acadêmicos e transbordar para as massas. Afinal, por que haveria os trabalhadores de se aquietarem ante as péssimas condições de trabalho e o confisco do seu conhecimento?

Nos anos 1950, iniciado o ciclo virtuoso de crescimento mundial, pôde-se vislumbrar que o grande formulador ideológico do capitalismo monopolista foi Henry Ford. As reformas implantadas em 1914 na Ford Motor Company - especialmente o the five dollars Day - tiveram a função de alertar para a necessidade da construção de um regime de remuneração que pudesse, por meio do consumo, dar vazão à capacidade de um sistema produtivo que se propunha revolucionário e, ao mesmo tempo, incompatível com a antiga relação salarial do capitalismo concorrencial. O fato de Ford ter pregado às dunas evidencia o quanto as ações isoladas são inconsistentes, quando o Estado não se atém para evitar as crises do capitalismo. De qualquer forma, o colapso de 1929 consagrou a política do the five dollars day, sinalizando que o capitalismo caminharia para o cadafalso caso não edificasse um sistema de regulação, sinal esse captado por Keynes, em 1936, quando elaborou o seu teorema da macroeconomia anticrise.

Trinta anos separam a adoção do the five dollars day e a conferência de Bretton Woods, tempo suficiente para que a catástrofe fosse evitada; mas, ainda que tardiamente, os donos do poder admitiriam que a mão invisível do mercado produz efeitos visíveis e, acima de tudo, trágicos. Mais tarde, porém, Polanyi $\mathrm{i}^{20}$ descobriria que, na verdade, a mão invisível nunca havia funcionado, posto que o capitalismo sempre dependera de um nível de regulação. Segundo Harvey, os efeitos práticos dessa constatação só se fariam sentir no segundo pós-guerra, posto que: "o problema da configuração e do uso próprios dos poderes do Estado só foi resolvido depois de 1945. Isso levou o fordismo à maturidade como um regime de acumulação plenamente acabado e distintivo"21

Toda a complexidade da economia e da política jamais chegaria traduzida às fábricas, onde os trabalhadores submetidos ao trabalho em migalhas clamavam por trabalho enriquecido, estabilidade, tempo livre, melhor remuneração e, fundamentalmente, o direito ao consumo. Mas, certamente, os efeitos combinados entre as intenções isoladas, porém visionárias, de Ford e a postura assumida mais tarde pelo Estado seriam um bálsamo para os espíritos, uma vez que a ideologia do consumo amenizaria os traumas causados pela ortodoxia do homem fracionado.

18 WEBER, M. A ética protestante e o espírito do capitalismo. São Paulo: Pioneira, 1967.

19 FRIEDMANN. O trabalho em migalhas.

20 POLANYI, K. A grande transformação. As origens de nossa época. Rio de Janeiro: Campus, 2000.

21 HARVEY, D. A condição pós-moderna, p.125. 


\section{O pioneirismo utilitarista da Escola de Chicago}

Como visto no primeiro tópico, por mais que a qualificação dos trabalhadores tenha sido uma constante no pensamento socialista do século XIX, ela permaneceu ignorada pela sociologia europeia na primeira metade do século XX, só recebendo o devido tratamento enquanto categoria de análise sociológica a partir do segundo pós-guerra. Não obstante e ironicamente, no mesmo período, a qualificação tornava-se um objeto de estudos no meio em que a destruição das qualidades da força de trabalho se apresentava mais pronunciada, ou seja, no próprio capitalismo norte-americano.

Nos Estados Unidos, nas primeiras décadas do século XX, o avanço da industrialização sob o taylorismo, assalariamento, subordinação da força de trabalho e a submissão de grandes contingentes urbanos às influências dos novos meios de comunicação produziu o fenômeno a que Ortega y Gasset ${ }^{22}$ definiu como massa, tema esse retomado mais tarde por E. Canetti, num grandioso tratado com enfoque no comportamento psicossocial. ${ }^{23} \mathrm{~A}$ rebeldia das massas tornou-se um problema crônico após 1929, quando o desemprego acometeu uma parte considerável da população, produzindo hordas nômades que erravam pelas cidades.

Pois, foram os problemas das massas - dentre eles, a violência urbana e a inquietação social que assolavam os grandes centros industriais como Boston, Detroit e Chicago - que mobilizaram os estudiosos norte-americanos a se debruçarem sobre esse tema como campo de estudos, dando conformação àquilo que se notabilizou como a Escola de Chicago. A Segunda Guerra Mundial possibilitou o contato entre os estudiosos europeus e os norte-americanos, posto que os primeiros buscaram guarida nos Estados Unidos, lá se deparando com uma sociologia preocupada em descobrir as melhores técnicas de controle social. Armand e Michèle Mattelart ${ }^{24}$ expuseram a consternação que acometeu M. Horkheimer e T. Adorno ao se depararem com os estudos no campo da comunicação social, desenvolvidos por Lazwell, Lazarsfeld e outros, nitidamente preocupados em descobrir as tendências presentes no comportamento das massas para melhor controlá-las.

Nesse contexto, também se desenvolveu um campo de estudos eufemisticamente denominado como sociologia industrial, preocupado em detectar o comportamento das massas no interior das fábricas sob o efeito da Administração Científica do Trabalho. Em sua temporada nos Estados Unidos durante a guerra, Georges Friedmann conheceu os estudos de Parsons, Merton e Mayo, sendo que a sua consternação em nada ficou devendo àquela que acometeu os dois pensadores da Escola de Frankfurt. Na sua visão, a sociologia industrial norte-americana era circunscrita ao universo da empresa, não vislumbrando o trabalho enquanto categoria social e, portanto, inserida no contexto da luta de classes. Assim, concluiu Friedmann, a razão primordial das pesquisas norte-americanas consistia em melhor compreender os antagonismos da produção baseada nos princípios tayloristas para o aperfeiçoamento da Administração Científica do Trabalho.

Não obstante, ele soube distinguir três elementos presentes na sociologia industrial que poderiam ser recuperados enquanto instrumentos metodológicos para o desenvolvimento de uma sociologia verdadeiramente crítica às condições do trabalho submetido ao taylorismo e ao maquinismo da Segunda Revolução Industrial;

22 ORTEGA y GASSET, J. A rebelião das massas. São Paulo: Martins Fontes, 2007.

23 CANETTI, E. Massa e poder. São Paulo: Companhia das Letras, 1995.

24 MATTELART, A. e MATELART. M. História das teorias da comunicação. São Paulo: Loyola, 2000. 
são eles: (i) a existência de um ramo da sociologia exclusivamente dedicado ao trabalho; (ii) a importância da observação empírica e dos dados estatísticos-quantitativos e; (iii) a qualificação da mão de obra como uma subárea dos estudos sobre o trabalho. Contrariamente a muitos dos sociólogos franceses que teciam ácidas críticas à sociologia industrial norte-americana, Friedmann soube filtrar os seus desvios ideológicos, preservando elementos interessantes da sua metodologia.

De volta à França, Friedmann juntou-se a P. Naville com o intuito de fundar um campo sociológico exclusivamente dedicado ao tema trabalho, de modo a dar uma resposta às novas questões postas pela civilização industrial e que emergiam com o capitalismo monopolista. Assim, apesar de a terminologia sociologia do trabalho ter sido empregada originalmente na França, essa subárea da sociologia nasceu nos Estados Unidos sob a terminologia sociologia industrial. E, a despeito das inúmeras críticas, amiúde, justificáveis, que se possa tecer à Escola de Chicago, não cabe, a bem da verdade, retirar-lhe o mérito de ter sinalizado à sociologia do trabalho francesa que a qualificação da força de trabalho constituía um campo fértil para a investigação social.

\section{O tributo da sociologia do trabalho francesa}

A civilização do maquinismo ${ }^{25} \mathrm{com}$ a qual Friedmann se defrontara nos Estados Unidos invadiu a Europa, especialmente a França, impulsionada pelo Plano Marshal e pela política de externalização do padrão norte-americano. Para Friedmann, embora os problemas franceses decorrentes dessa etapa do capitalismo fossem os mesmos verificados nos Estados Unidos, a sociologia do trabalho francesa não poderia se utilizar integralmente dos mesmos métodos empregados pela Escola de Chicago. Em outras palavras, a crítica marxista deveria ser renovada, com o direcionamento do foco para as contradições mais agudas do capitalismo que eram potencializadas com a aplicação da Administração Científica do Trabalho. Entretanto, tal renovação não desprezaria os elementos considerados como positivos da sociologia industrial.

Não é de se estranhar que o tema qualificação profissional tenha ganhado uma dimensão proeminente e uma centralidade ímpar nos trabalhos de Friedmann e de Naville, à medida que o padrão norte-americano foi-se consolidando na Europa, em especial, na França. Certamente que a origem marxista, em primeira instância, os conectou ao tema, tendo em vista que a discussão em torno dele, como demonstrado, é historicamente indissociada do debate sobre a transformação social. Todavia, é inegável que, tendo as suas pesquisas como foco os efeitos sociais provocados pela Administração Científica do Trabalho, a inclinação para o estudo sobre a qualificação da força de trabalho tenha-se tornado um caminho inexorável. Assim, após ter permanecido por meio século circunscrito à retórica politécnica da União Soviética e ao pragmatismo pró-taylorista da Escola de Chicago, o debate sobre a qualificação profissional ressurgiu na França enquanto categoria de análise sociológica e - o que é mais sintomático - resgatado pelas mãos do marxismo, campo filosófico que o suscitara no passado.

Como visto anteriormente, Owen tentou desmistificar que a desqualificação da força de trabalho fosse algo inexorável e decorrente de uma evolução natural,

25 Termo empregado por G. Friedmann, referindo-se ao conjunto de valores ensejado pelo padrão-norteamericano. 
defendendo a tese de que ela poderia ser revertida por mudanças nas formas de produção e de educação. Essa premissa - assumida por Marx e Engels, sob o condicionante de que ela só seria possível no socialismo - até então havia sido defendida enquanto um axioma, sem nenhuma formulação de caráter científico que, em última instância, explicasse a contento o que afinal determina a qualificação. As interrogações, portanto, que moviam a sociologia do trabalho francesa com a disseminação do padrão norte-americano na Europa, eram: que forças no interior da produção da riqueza impulsionam a qualificação da força de trabalho? Existiriam leis que determinariam a qualificação necessária de acordo com os estágios de desenvolvimento da produção? A qualificação ocorre simplesmente por uma determinação política por parte dos agentes produtores?

Concluiu Friedmann que, apesar de a qualificação da força de trabalho ser, em primeira instância, uma escolha social, duas forças atuantes na produção da riqueza também a influenciam: a evolução dos meios de produção e a divisão do trabalho. Essa constatação advém da observação de que o refluxo do conhecimento dos trabalhadores foi-se acentuando ao longo do modo de produção capitalista, à medida que a maquinaria e a divisão do trabalho se faziam presentes em níveis mais pronunciados. Assim, a manufatura, a grande indústria e o taylorismo mantêm em comum a diminuição das habilidades, conforme a introdução da maquinaria e a fragmentação das tarefas se aprofundam. Tendo trabalhado conjuntamente a Naville e muitos outros, Friedmann adota a tese do primeiro - que se tornaria predominante na sociologia do trabalho francesa - sobre os determinantes da qualificação da força de trabalho, cuja definição mais elaborada pode ser observada na seguinte formulação de Naville; segundo o autor:

\footnotetext{
"Mais a sociedade desenvolve as forças produtivas, mais o volume da população aumenta, mais crescem os meios de produção sedentários e duráveis, mais se ramifica a divisão técnica e a divisão social do trabalho, mais as necessidades se multiplicam, mais certas ocupações definidas são consideradas mais qualificadas em relação às outras (...). A qualificação tomou assim um sentido particular na sociedade industrial moderna, aquela que nasceu da revolução social e da técnica ocidental desde o século XVI, a medida em que se desenvolveu a influência da técnica sobre a vida social. O técnico qualificado instalou-se, aos poucos, no centro dos valores sociais, e pôs-se a desafiar o prestígio tradicional do político, do sábio ou do padre (...). Tudo isso é inseparável do desenvolvimento do maquinismo e da instrução, isto é, de um certo uso do tempo e da acumulação de experiências adquiridas no decorrer do tempo. A qualificação dos empregos deveria receber, portanto, uma certa marca do regime do salariado, do capitalismo e da propriedade pessoal dos meios de produção". ${ }^{26}$
}

Segundo os dois estudiosos, o maquinismo mantém uma relação de reciprocidade dialética com a divisão do trabalho; entretanto, o progresso das técnicas de produção tem um peso considerável à medida que estimula e fomenta a divisão do trabalho, sendo que essa só pode se realizar com o desenvolvimento daquele. Obviamente, salienta Friedmann, que por trás dessa relação dialética encontrase uma determinação política por parte dos agentes produtores; pois, em última instância, o próprio desenvolvimento da técnica é um produto das decisões humanas decorrentes das condições dadas pelo desenvolvimento capitalista. Em outras palavras, a introdução da técnica também decorre de escolhas sociais. As- 
sim, além da decisão política, a qualificação também é condicionada à complexidade do trabalho, sendo essa inversamente proporcional à divisão do trabalho, posto que o aprofundamento da segunda implica o refluxo da primeira.

Temendo que tal premissa pudesse sofrer uma conotação determinista como aquela que Braverman formularia mais tarde, Friedmann adverte que, evidentemente, esse pressuposto não pode ser considerado de uma forma determinista, devendo, primordialmente, levar-se em conta os inúmeros condicionantes de ordem econômica, social, política e cultural que envolvem os atores na produção da riqueza social. A determinante máxima da qualificação da força de trabalho é a escolha social; todavia, essa opção deve ser ancorada em condicionantes dados pelo desenvolvimento da técnica e pela divisão do trabalho. ${ }^{27}$

Até meados dos anos 1950, o debate sobre a qualificação da força de trabalho avançava, porém, muito mais no campo dos estudos que no atitudinal por parte dos governos. É presumível que a expansão dos sistemas educacionais que acompanhava a implantação das políticas sociais nos Estados Unidos e, principalmente, na Europa, tenha provocado o comodismo das burocracias estatais para com a qualificação média da força de trabalho, por considerar que a competitividade ocidental estaria assegurada pela elevação dos níveis de escolarização formal.

Mas, eis que o equilíbrio da Guerra Fria pendeu inesperadamente contra o Ocidente quando, em 1957, a União Soviética pôs em órbita o satélite Sputinik. A capacidade científica e tecnológica da URSS fora desprezada, mas para os soviéticos, a meta de colocar armas de destruição em massa no espaço apontando para os Estados Unidos vinha sendo perseguida sistematicamente. Até então, as notícias que chegavam do Leste davam conta que o modelo politécnico estava provocando uma revolução educacional, sendo que, para o Ocidente, o Sputinik era a evidência da existência de uma relação de causa e efeito entre qualificação da força de trabalho e o vanguardismo científico e tecnológico soviético.

Todavia, a despeito do fracasso do politecnismo, o sucesso do Sputinik comprovaria que a retórica soviética não teria sido em vão, ainda que para impulsionar os sistemas ocidentais de qualificação profissional. Preocupados com a perda de competitividade, os Estados Unidos realizaram a Conferência de Woods Hole, em Massachussetts, com o objetivo de propor a reformulação dos currículos da educação básica e secundária, com a introdução de estudos avançados de ciências. Mas, a Europa não se deixaria ficar para trás: ainda em 1957, a recém-criada Comunidade Econômica Europeia (CEE) lançou o Programa de Ensino e Formação Profissional, acelerado em 1960, cuja decisão foi tomada na reunião do Conselho de Ministros da CEE. ${ }^{28}$

O aprofundamento da industrialização nos Estados Unidos e na Europa, a partir dos anos 1960, produziu o fenômeno - presenciado por Friedmann, Naville, Rolle, Touraine e outros - que desferiria um golpe duro no argumento de Taylor sobre a necessidade da desqualificação da força de trabalho, posto que o próprio desenvolvimento capitalista gestava as condições para a recomposição das tarefas e, consequentemente, a elevação das potencialidades dos trabalhadores. Esse fenômeno ocorria sob a automação de base eletromecânica.

Com a automação eletromecânica, o posto de trabalho e a máquina perderam importância, uma vez que os sistemas eletromecânicos possibilitaram a inter-

27 FRIEDMANN. O trabalho em migalhas, p.181

28 WOLLSCHLÄGER, N. "Da divergência à convergência: uma história da formação profissional na Europa". Revista Europeia de Formação Profissional n³2. Tessalônica: Cedefop, 2004. 
conexão de várias máquinas, fazendo com que a produção dependesse de uma totalidade conjugada de postos de trabalho, máquinas e demais instrumentos; ou seja, a produção tornou-se dependente do processo industrial. Assim, também se tornaram fluidas e sem sentido as fronteiras que anteriormente delimitavam os postos de trabalho e as máquinas, ficando igualmente desprezível a ideia de que a desqualificação dos trabalhadores era necessária. Em curso inverso, ganhou força a ideia de que a qualificação mais ampla seria necessária, uma vez que a intervenção no processo requer visões e aptidões abrangentes e pluridimensionais, porque o operador passava a lidar com uma totalidade muito mais complexa. A conclusão apresentada pela sociologia do trabalho francesa é que a automação demole a fragmentação taylorista do trabalho, possibilitando - mediante a consolidação do processo industrial - um alargamento das tarefas, o que exige um nível mais elevado de qualificação dos trabalhadores.

Por volta dos anos 1960, a idolatria à parcelização do trabalho já não fazia sentido, posto que ela já estava sob fogo cerrado, pelos seguintes eventos: (i) o comportamento repulsivo dos trabalhadores, que desenvolviam todas as modalidades de patologias em razão da brutalidade do método de tratar seres humanos como parte da maquinaria; (ii) o incremento do ferramental de base eletromecânica que, ao eleger o processo como o elemento central da produção, deitou por terra a fragmentação laboral centrada na máquina e no posto de trabalho e; (iii) o surgimento, no Japão, de uma nova concepção industrial que, tendo como parâmetros iniciais a recomposição das tarefas, rearranjo da cadeia de fornecedores, incremento tecnológico e a cooptação dos trabalhadores, impactaria o Ocidente, tornando-se, nas décadas seguintes, um dos maiores críticos do taylorismo.

Mas, seria a automação o instrumento pelo qual a utopia do homem produtivamente emancipado, há muito acalentada, se consagraria? A automação poderia eliminar em definitivo e em sua totalidade o trabalho parcelizado? Segundo Friedmann, a automação tem o potencial para eliminar por completo o trabalho em migalhas, mas não nas condições dadas pelo modo de produção capitalista. A despeito de todas as suas virtudes, no capitalismo, a automação só tem a propriedade de enriquecer o trabalho e de elevar a qualificação - re-espiritualizar - para uma seleta casta de trabalhadores alocados nos subsetores mais modernos da economia, enquanto que o trabalho em migalhas - desespiritualizado - tende a prevalecer nos nichos mais atrasados da produção. A automação conduz, portanto, a uma dupla evolução contraditória caracterizada pela co-existência entre uma minoria qualificada praticando o trabalho enriquecido e a maioria desqualificada, executando trabalhos rotinizados, parcelizados e desprovidos de qualquer espiritualidade; a automação conduz à polarização das qualificações. ${ }^{29}$

Segundo Friedmann, para a consagração do homem produtivamente emancipado seria necessário: (i) o questionamento dos princípios tayloristas; (ii) a transformação radical do capitalismo que permitisse a ruptura para com a dicotomia concepção-realização; (iii) a revalorização da educação e; (iv) a diminuição da jornada de trabalho. Creio que três dessas condições também se aplicam ao propósito de inquirir a educação profissional no Brasil; são elas: o questionamento do taylorismo, a revalorização da educação e a diminuição da jornada de trabalho.

A crítica ao taylorismo foi exaurida, não tendo mais argumentos adicionais

29 A bem da verdade, Friedmann não emprega a expressão polarização das qualificações, sendo que o seu uso neste contexto é uma interpretação minha, tentando sintetizar a sua ideia sobre o comportamento da qualificação da força de trabalho mediante a introdução da automação. 
que evidenciem o seu aspecto desagregador. A educação, no entanto, possui uma relevância fundamental para a qualificação profissional, sendo que o debate em torna dela, nessa perspectiva, ganha um peso crescente na sociedade brasileira. Friedmann acreditava que sem o auxílio da boa educação de base o domínio sobre as técnicas de produção torna-se deficiente; isso é objetivo nas suas palavras quando diz: "Mas, a técnica não será dominada se o homem, ajudado por um sábio, por um imenso investimento na educação, não se dominar a si próprio". $3^{\circ 0}$ Confirmando o quanto essa é uma ideia axiomática, desde a primeira até a última página, esse inquérito insiste em analisar a formação profissional indissociadamente da educação formal.

Desde o século XIX, quando veio à tona resgatada por P. Lafargue, a questão do tempo livre esteve presente nas demandas dos trabalhadores muito mais como um direito ao lazer, às atividades lúdicas e até mesmo, como reivindicou Lafargue, ${ }^{31}$ um direito à preguiça. No entanto, ela tem outra dimensão tão nobre quanto as reivindicadas, qual seja a de liberar os trabalhadores para a educação e para a qualificação. Em trabalho anterior, ${ }^{32}$ chamei a atenção para a elevada jornada de trabalho praticada no Brasil - que, em algumas regiões, beirava as 5oh semanais - como um entrave à elevação da educação geral e da qualificação dos trabalhadores. Para um país em que as taxas de evasão escolar das crianças e dos adolescentes são elevadíssimas e que, quando adultos, esses tendem a regressar à escola quando já inseridos no mercado de trabalho, a jornada de trabalho efetivamente praticada deve ser revista sob o risco de uma degradação pronunciada da qualidade da força de trabalho.

Antes de concluir a apresentação do tributo da sociologia do trabalho francesa para com os estudos sobre a qualificação profissional, creio ser fundamental a exposição de uma das suas premissas mais interessantes e, ao mesmo tempo, controversa, e que rendeu aos seus formuladores o estigma de deterministas: trata-se da importância concedida à tecnologia.

A penetração da automação de base eletromecânica na França, no início do ciclo virtuoso do segundo pós-guerra, aguçou os sentidos de Friedman, Naville, Rolle e os demais que com eles compartilhavam a tarefa da edificação de um campo de estudos sociológicos dedicado ao trabalho. A radicalidade pela qual a automação eletromecânica tensionava a Administração Científica do Trabalho levou os pesquisadores a direcionar o foco das investigações para a tecnologia. Essa ideia - que, talvez, seja a mais benfazeja dentre as contribuições da sociologia industrial sobre os estudiosos - enriqueceu, sobremaneira, os seus trabalhos; todavia, poucos atentaram para esse aspecto da sua obra, senão para criticá-los.

A preocupação em reservar ao estudo sobre a tecnologia o lugar merecido dentre os demais temas da sociologia do trabalho rendeu aos sociólogos, especialmente a Friedmann, um rótulo: diziam os seus críticos que o seu pensamento era, de tal forma, contaminado pelo determinismo tecnológico ao ponto de desfocar o objeto de análise e distorcer os resultados das suas pesquisas. Todavia, a crítica não o dissuadiu de enxergar a tecnosfera como a fonte de outras relações sociais relevantes, que se somam às tradicionalmente existentes entre o capital

30 FRIEDMANN, G. O futuro do trabalho humano. Apud TARTUCE, G.L B.P. O que há de novo no debate da 'qualificação do trabalho'? Reflexão sobre o conceito com base nas obras de Georges Fiedmann e Pierre Naville. Dissertação de Mestrado, FFLCH, USP, 2002, p.108

31 LAFARGUE, P. O direito à preguiça. A religião do capital. São Paulo: Kairós, 1983.

32 GOMES, C. Produção flexível e degradação da força de trabalho no Brasil. Dissertação de Mestrado. Universidade Estadual de Campinas - FE, 2006. 
e o trabalho. No terceiro capítulo de o Tratado de sociologia do trabalho - escrito conjuntamente por Georges Friedmann e F. I. Isambert e denominado Sociologia do trabalho e Ciências Sociais ${ }^{33}$ - a relação entre o trabalho e a tecnologia é explorada com maior profundidade, explicitando como o método de investigação sociológica não pode prescindir do estudo sobre as condições técnicas incidentes sobre a produção, pois, "todo trabalho depende das condições técnicas". ${ }^{34}$ Para os autores, a relação entre a técnica e os aspectos sociais do trabalho é, de tal forma, estreita que, todo processo de mudança num, consequentemente, repercute noutro, sendo indispensável que a sociologia do trabalho não a subestime. ${ }^{35}$

Portanto, ao evoluir, as condições técnicas contribuem para a remodelação dos processos produtivos e para a readaptação das relações sociais de produção, requerendo ou possibilitando novas formas de organização do trabalho e, especialmente, um nível diferenciado de qualificação dos trabalhadores, entre outros tantos impactos. Isso porque, "desde as suas origens e através de todas as etapas da sua evolução, até os primórdios da automatização (...), o trabalho está inscrito na forma da ferramenta e da máquina". ${ }^{36}$ Assim, possuindo a técnica tamanha importância para o trabalho, "a tecnologia tem, portanto, por objeto estudar, na mesma diligência, o instrumento e a maneira de utilizá-lo. Considerada na plenitude da sua vocação, portanto, ela é, ou deveria ser uma Ciência Social". ${ }^{37}$ A própria evolução da técnica, em si, encerra uma relação social e o seu emprego nos processos de produção só é possível pelo estabelecimento de novas relações sociais entre os agentes produtores. Assim, "as ações recíprocas entre técnicas e fatores sociais tecem laços múltiplos entre a tecnologia e a história das técnicas, de um lado, e a sociologia do trabalho, de outro". ${ }^{38}$

Todavia, reafirmando a sua intenção de fugir às interpretações deterministas, Friedmann e Isambert advertem que a tecnologia é apenas um meio pelo qual as forças sociais atuam para o enriquecimento do trabalho. Contra uma possível interpretação desavisada sobre um papel redentor da tecnologia, Friedmann alerta que não se deve cair na tentação de alguns sonhadores que "preferem substituir a observação rigorosa por postulados líricos que nos projetam para muito longe no futuro". 39

\section{Conclusão}

Friedmann, Naville e os demais estudiosos da sociologia do trabalho francesa que com eles compartilharam a defesa das teorias e dos argumentos aqui apresentados viram apenas a ponta de um iceberg, posto que o desenvolvimento tecnológico - em especial a automação - e a divisão do trabalho apresentariam uma profunda transformação no final do século XX, provocando nos novos pesquisadores um tensionamento ainda mais reflexivo sobre o destino do trabalho e da qualificação.

É um desafio para os estudiosos olhar para os fenômenos e filtrar os

33 FRIEDMANN, G. e ISAMBERT, F. I. "Sociologia do trabalho e ciências sociais". In FRIEDMANN, G. e NAVILLE, P. Tratado de sociologia do trabalho. Vol. I. São Paulo: Cultrix, 1973.

34 FRIEDMANN e ISAMBERT. "Sociologia do trabalho", p. 80.

35 FRIEDMANN e ISAMBERT. "Sociologia do trabalho", p. 81.

36 FRIEDMANN e ISAMBERT. "Sociologia do trabalho", p. 80.

37 FRIEDMANN e ISAMBERT. "Sociologia do trabalho", p. 81.

38 FRIEDMANN e ISAMBERT. "Sociologia do trabalho", p. 81.

39 FRIEDMANN. O trabalho em migalhas, p.177. 
elementos gerais do processo de evolução das sociedades daqueles específicos dos momentos conjunturais. Todavia, considerando que as formulações da sociologia do trabalho francesa foram feitas num momento em que o desenvolvimento das forças produtivas apenas dava início ao tensionamento da ortodoxia taylorista, aos seus estudiosos cabe o mérito de vislumbrar as tendências estruturais gerais da qualificação da força de trabalho, presentes na nova dinâmica industrial que emergia sob a égide do automatismo. Traduzindo, esse mérito consiste em: (i) identificar ou formular com clareza que a qualificação é, em última instância, correlacionada ao desenvolvimento tecnológico e à divisão do trabalho, mas que, como ambos, ela própria também é decorrente de escolhas sociais e; (ii) que o automatismo, em si, contém forças disruptivas com potencial para tensionar e demolir por completo a fragmentação taylorista, possibilitando o alargamento das tarefas e o enriquecimento do trabalho.

Assim como Owen, Friedmann e Naville traduzem para a sua obra o traço humanista das suas personalidades, posto que, a todo tempo, a brutalidade do taylorismo é denunciada em defesa da autorrealização humana. Tal como Marx e Engels, os estudiosos franceses se utilizam do método dialético para a crítica ao capitalismo monopolista, responsável pelo trabalho em migalhas. Contudo, diferentemente dos demais, Friedmann e Naville viveram num tempo em que as grandes transformações em curso lhes possibilitaram a constatação prática que o homem fracionado poderia ser minimamente reconstituído. 
